\title{
A general ligand-assisted self-assembly approach to crystalline mesoporous metal oxides
}

\author{
Danyang Feng ${ }^{1}$, Tu-Nan Gao ${ }^{1}$, Meihong Fan' ${ }^{1}$, Ang Li ${ }^{1}$, Kaiqian Li ${ }^{1}$, Tao Wang ${ }^{1}$, Qisheng Huo ${ }^{1}$ and Zhen-An Qiao ${ }^{1}$
}

\begin{abstract}
Mesoporous transition metal oxides with high crystallinity and large pore volumes were successfully synthesized by a widely applicable ligand-assisted self-assembly approach. In this approach, a carboxyl-containing ligand is employed as a coordination agent to retard the hydrolysis and condensation rates of the precursors. The ligands interact with the PEO chains of P123 via hydrogen bonds, which cooperatively ensures the controllable co-assembly of template micelles and the metal source during solvent evaporation. The X-ray diffraction, transmission electron microscopy, and nitrogen sorption results show that the obtained mesoporous metal oxides are constructed from numerous highly crystalline nanoparticles and possess close-packed mesostructures with uniform pore size distributions. A series of mesoporous transition metal oxides $\left(\mathrm{CO}_{3} \mathrm{O}_{4}, \mathrm{Mn}_{2} \mathrm{O}_{3}, \mathrm{Fe}_{3} \mathrm{O}_{4}, \mathrm{NiO}, \mathrm{CuO}, \mathrm{ZnO}\right.$, and $\left.\mathrm{Cr}_{2} \mathrm{O}_{3}\right)$ and multi-metal oxide composite materials $\left(\mathrm{CO}_{3} \mathrm{O}_{4} / \mathrm{Fe}_{3} \mathrm{O}_{4}, \mathrm{CO}_{3} \mathrm{O}_{4} / \mathrm{NiO}\right.$, and $\left.\mathrm{Fe}_{3} \mathrm{O}_{4} / \mathrm{NiO}\right)$ were successfully synthesized. By employing the crystalline $\mathrm{CO}_{3} \mathrm{O}_{4} / \mathrm{Fe}_{3} \mathrm{O}_{4}$ composites as electrocatalysts, high catalytic activity can be achieved during the oxygen evolution reaction. A low overpotential of $322 \mathrm{mV}$ at a current density of $10 \mathrm{~mA} \mathrm{~cm}{ }^{-2}$ is exhibited, which shows that this approach has great significance not only in synthesis but also in electrocatalysis.
\end{abstract}

\section{Introduction}

Mesoporous transition metal oxides possessing a large surface area and high degree of crystallization have attracted extensive attention because of their remarkable properties and promising applications in gas sensing, energy storage, catalysis, and photodetection ${ }^{1-8}$. Various strategies have been used to synthesize mesoporous transition metal oxides. One promising route is the hard template approach, which employs mesoporous silica or carbon as a rigid template to introduce the desired mesoporous structure and removes the template by etching or calcination to finally obtain mesoporous transition metal oxides $^{9-12}$. This approach can synthesize unique crystalline and ordered mesoporous metal oxides but still has some deficiencies. For example, the mesoporous structures of the metal oxides depend on the frameworks of the hard

\footnotetext{
Correspondence: Zhen-An Qiao (qiaozhenan@jlu.edu.cn)

${ }^{1}$ State Key Laboratory of Inorganic Synthesis and Preparative Chemistry,

College of Chemistry, Jilin University, Changchun, Jilin 130012, China
}

templates, and only a few hard templates are available for use. Moreover, the procedure is costly, laborious, and low yielding. To overcome these limitations, a soft-templating approach was proposed, i.e., the evaporation-induced selfassembly (EISA) route. For instance, Fan et al. prepared multicomponent mesoporous metal oxides in a versatile sol-gel solution consisting of acetic acid ${ }^{13}$. Suib et al. reported an inverse micelle synthesis system to prepare mesoporous metal oxides ${ }^{14}$. Mesoporous materials with diverse morphologies and tunable pore sizes have been prepared by controlling the synthesis conditions and the properties of the template molecules based on soft templating ${ }^{15,16}$. This approach is flexible and effective for largescale synthesis. However, the mesostructures are apt to shrink and even collapse during formation of the mesostructure by calcination and removal of the organic templates. The pore walls of mesoporous transition metal oxides formed by the soft-templating approach are almost amorphous or semi-crystalline, which may impede their 
further applications. Moreover, uncontrolled hydrolysis and condensation of transition metal sources, such as alkoxides, can result in poorly structured materials due to the rapid formation of dense, cross-linked inorganic networks. Carboxylic acid-containing ligands can be used as structure-directing agents in soft-templating approaches $^{17,18}$, and the ligand-assisted EISA method developed by Deng and coauthors provides a new idea for the synthesis of stable and crystalline mesoporous oxides ${ }^{19}$. Although great advances have been made in the synthesis of several mesoporous transition metal oxides, the development of a universal method to synthesize thermally stable and highly crystalline mesoporous metal oxides is still a great challenge.

Herein, we demonstrate a general effective ligandassisted self-assembly synthesis strategy to prepare mesoporous transition metal oxides composed of highly crystalline nanocrystals with high surface area and unique stability by using the triblock copolymer P123 as a template, metal nitrate as a precursor, and acidic n-butanol as the reaction medium. Remarkably, mesoporous transition metal oxides were prepared by coordinating the metal precursors with carboxyl-containing ligands to control the hydrolysis and condensation rates and decrease the degree of cross-linking of the metal gel networks. Meanwhile, the ligand molecules attached to the PEO chains through $\mathrm{H}$ bonds hinder the local motion of the PEO chains. The slow assembly between template micelles and the inorganic metal source allows the formation of well-defined mesostructures. This general method was successfully used to synthesize a series of mesoporous transition metal oxides, including mesoporous $\mathrm{Cr}_{2} \mathrm{O}_{3}, \mathrm{Mn}_{2} \mathrm{O}_{3}, \mathrm{Fe}_{3} \mathrm{O}_{4}$, $\mathrm{Co}_{3} \mathrm{O}_{4}, \mathrm{NiO}, \mathrm{CuO}$, and $\mathrm{ZnO}$. It is worth mentioning that mesoporous $\mathrm{CuO}$ and $\mathrm{Cr}_{2} \mathrm{O}_{3}$ are both obtained for the first time without using a hard template. Additionally, mesoporous multi-metal oxide composites (e.g., $\mathrm{Co}_{3} \mathrm{O}_{4} /$ $\mathrm{Fe}_{3} \mathrm{O}_{4}, \mathrm{Co}_{3} \mathrm{O}_{4} / \mathrm{NiO}$, and $\mathrm{Fe}_{3} \mathrm{O}_{4} / \mathrm{NiO}$ ) can also be acquired by this versatile strategy. Excellent electrochemical performance was observed due to the existence of mesoporous structures in these materials. The as-synthesized $\mathrm{Co}_{3} \mathrm{O}_{4}$ and $\mathrm{Co}_{3} \mathrm{O}_{4} / \mathrm{Fe}_{3} \mathrm{O}_{4}$ composites are highly active materials for the electrocatalytic oxygen evolution reaction (OER).

\section{Materials and methods}

\section{Synthesis of mesoporous metal oxides}

All the mesoporous metal oxides were synthesized by the ligand-assisted self-assembly process using citric acid/ ascorbic acid as a chelating agent, concentrated $\mathrm{HNO}_{3}$ to adjust the $\mathrm{pH}$, and $\mathrm{n}$-butanol as a solvent. Metal nitrate and the triblock copolymer Pluronic P123 were employed as the precursor and the template, respectively. In a typical synthesis of mesoporous $\mathrm{Co}_{3} \mathrm{O}_{4}, 1.36 \times 10^{-4} \mathrm{~mol}$ of $\mathrm{P} 123$, $5 \mathrm{mmol}$ of citric acid, and $16 \mathrm{mmol}$ of concentrated $\mathrm{HNO}_{3}$ were dissolved in $70 \mathrm{mmol}$ of 1-butanol solution under magnetic stirring followed by the addition of $2.5 \mathrm{mmol}$ of the inorganic source $\mathrm{Co}\left(\mathrm{NO}_{3}\right)_{2} \cdot 6 \mathrm{H}_{2} \mathrm{O}$. The mixture was stirred vigorously for several hours at room temperature until a transparent sol formed. The sol was transferred into a Petri dish (diameter $90 \mathrm{~mm}$ ), and the solvent was evaporated in a $120^{\circ} \mathrm{C}$ oven over $4 \mathrm{~h}$. Then, the as-synthesized pink powder product was removed and calcined in air by a stepwise pyrolysis approach at $150^{\circ} \mathrm{C}$ for $4 \mathrm{~h}$ (ramp rate $\left.2^{\circ} \mathrm{C} / \mathrm{min}\right), 250^{\circ} \mathrm{C}$ for $2 \mathrm{~h}\left(\right.$ ramp rate $2{ }^{\circ} \mathrm{C} / \mathrm{min}$ ), and $350^{\circ} \mathrm{C}$ for $2 \mathrm{~h}$ (ramp rate $2^{\circ} \mathrm{C} / \mathrm{min}$ ), resulting in the highly crystalline mesoporous $\mathrm{Co}_{3} \mathrm{O}_{4}$ product.

\section{Fabrication of the oxygen evolution reaction working electrode}

Ten milligrams of catalyst powder was dispersed in $300 \mu \mathrm{L}$ of isopropyl alcohol and ultrasonically mixed for $\sim 30 \mathrm{~min}$. One microliter of the obtained catalyst slurry was dropped on a polished GC electrode, and then, $2 \mu \mathrm{L}$ of Nafion (5 wt\% in ethanol, Alfa Aesar) was cast onto the above coating and dried in air at room temperature (this yielded an approximate metal loading of $0.5 \mathrm{mg} \mathrm{cm}^{-2}$ ).

\section{Characterization}

Field-emission transmission electron microscopy (TEM), high-resolution TEM (HRTEM), and selected-area electron diffraction (SAED) images were obtained using a FEI Tecnai G2 F20 s-twin D573 field-emission TEM operated at 200 kV. EDX spectra were acquired using a Phillips CM200 TEM instrument $(200 \mathrm{kV})$. Powder X-ray diffraction (XRD) patterns were collected on a Rigaku 2550 diffractometer with $\mathrm{Cu} \mathrm{K} \alpha$ radiation at $40 \mathrm{kV}$ and $100 \mathrm{~mA}(\lambda=1.5418 \AA)$. $\mathrm{N}_{2}$ adsorption-desorption isotherms were measured at $-196^{\circ} \mathrm{C}$ on a NOVA 4200e. Samples were degassed at $120^{\circ} \mathrm{C}$ for a minimum of $4 \mathrm{~h}$ prior to analysis. The specific surface area and pore size distributions were calculated using the Brunauer-Emmett-Teller (BET) equation and the Barrett-Joyner-Halenda (BJH) model from the adsorption branches. Thermogravimetric analysis (TGA) was performed on a TGA Q500 thermogravimetric analyzer in air over the temperature range of $30-800{ }^{\circ} \mathrm{C}$ at a heating rate of $10^{\circ} \mathrm{C} \mathrm{min}^{-1}$. Inductively coupled plasma emission spectroscopy was carried out using an ICP-OES, PerkinElmer OPTIMA 3300DV. Infrared (IR) spectra were recorded using a Nicolet Impact 410 FTIR spectrometer over the wavelength range of $400-4000 \mathrm{~cm}^{-1}$ using $\mathrm{KBr}$ pellets.

Electrochemical measurements were performed on a corrected electrochemical workstation (CHI660E) in a conventional three-electrode system containing a $1 \mathrm{M}$ $\mathrm{KOH}$ electrolyte. The coated glassy carbon disk electrode (3-mm diameter, disk: $0.071 \mathrm{~cm}^{2}$ ) served as the working electrode. A $\mathrm{Hg} / \mathrm{HgO}$ electrode and high-surface-area $\mathrm{Pt}$ mesh were used as the reference and counter electrodes, 


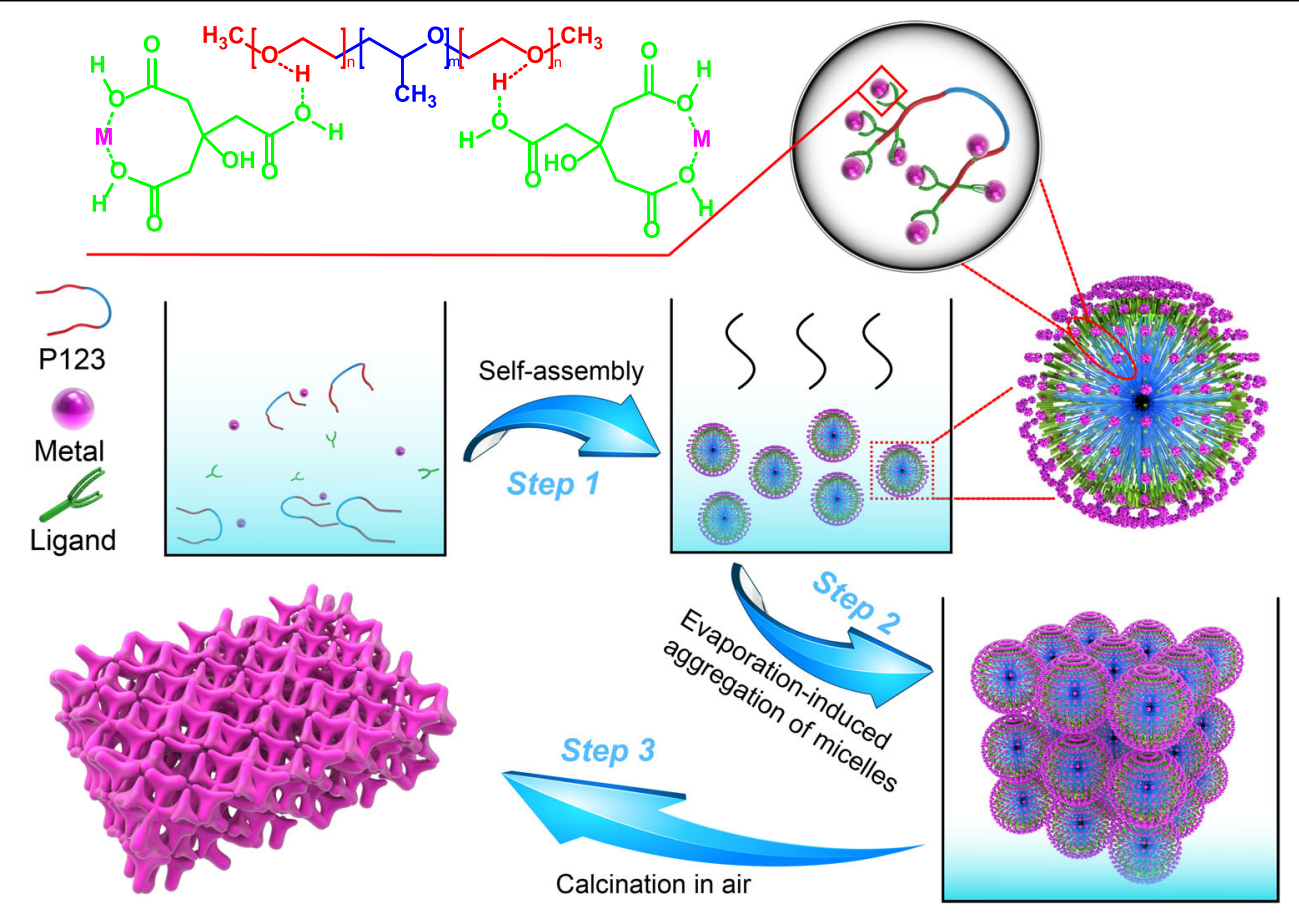

Scheme 1 Schematic illustration of the formation process for mesoporous transition metal oxides

respectively. Linear sweep voltammetry (LSV) curves of different catalysts at scan rates of $5 \mathrm{mV} \mathrm{s}^{-1}$ were obtained in $1 \mathrm{M} \mathrm{KOH}$ electrolyte over a potential window of $0.296-0.800 \mathrm{~V}$, and the voltage was corrected according to the $\mathrm{iR}$ loss from the solution resistance.

\section{Results and discussion}

Scheme 1 shows a schematic illustration of the fabrication process of the crystalline mesoporous transition metal oxides. The homogeneous mesostructure was prepared by assembling the carboxyl-coordinated inorganic precursors with an amphiphilic surfactant via a ligandassisted self-assembly route. In the first stage, inorganic species were dissolved in an acidic n-butanol/P123/carboxylic ligand mixture solution, and then, the obtained transparent sol was dried in an oven for several hours. In this process, the strong aqueous acid $\mathrm{HNO}_{3}$ was used as the charge intermediate between the inorganic metal clusters and surfactants to hinder condensation. The carboxyl-coordinated transition metal complex was fabricated as an optimized precursor, which effectively retarded the hydrolysis and condensation rates. Due to the existence of coordination bands, the inorganic metal sources were stabilized over the growth period, which led to controllable co-assembly between the precursors and surfactant micelles ${ }^{20}$. In addition, the ligands interacted with the PEO chains of P123 through direct hydrogen bonds between the carboxylic hydroxyl groups and the ether groups of $\mathrm{PEO}^{21}$. During the continuous evaporation of n-butanol, mesostructures were gradually formed by both coordination-bonding interactions and hydrogen-bonding interactions. By removing the triblock copolymer templates after a series of calcination processes in air, the crystalline mesoporous transition metal oxides were finally obtained.

The scheme was confirmed by the Fourier transforminfrared (FTIR) spectrum. Taking the synthesis of $\mathrm{Co}_{3} \mathrm{O}_{4}$ as an example, the $\mathrm{C}=\mathrm{O}$ vibrational peaks for uncoordinated carboxylic acid appear at $1707 \mathrm{~cm}^{-1}$ and $1753 \mathrm{~cm}^{-1}$ (Fig. 1e black line), while the $\mathrm{C}=\mathrm{O}$ vibrational peaks for the coordinated sample appear at $1386 \mathrm{~cm}^{-1}, 1618 \mathrm{~cm}^{-1}$, and $1738 \mathrm{~cm}^{-1}$ (Fig. 1e blue line). The bands at $1386 \mathrm{~cm}^{-1}$ and $1618 \mathrm{~cm}^{-1}$ can be attributed to the asymmetric and symmetric stretching vibrations of the coordinated carboxylate group. The band at $1738 \mathrm{~cm}^{-1}$ can be assigned to the $\mathrm{C}=\mathrm{O}$ stretching mode of the nondissociated carboxylate group. Moreover, for the coordinated sample, the $\mathrm{O}-\mathrm{H}$ vibrational peaks of $-\mathrm{COOH}$ at $\sim 3500 \mathrm{~cm}^{-1}$ and $2600 \mathrm{~cm}^{-1}$ (Fig. 1e black line) almost disappeared. The above observations suggest that the $\mathrm{O}-\mathrm{H}$ bands of the carboxyl groups were partly deprotonated and the carboxyl groups coordinated to the Co atoms. After thermal oxidation in air, the strong adsorption bands at $650 \mathrm{~cm}^{-1}$ and $569 \mathrm{~cm}^{-1}$ (Fig. 1e red line) can be assigned to the vibration of $\mathrm{Co}-\mathrm{O}$ in cobalt oxide, confirming that the conversion process involves the transition from the intermediate cobalt carbonate to cobalt oxide through decomposition $^{22}$. 

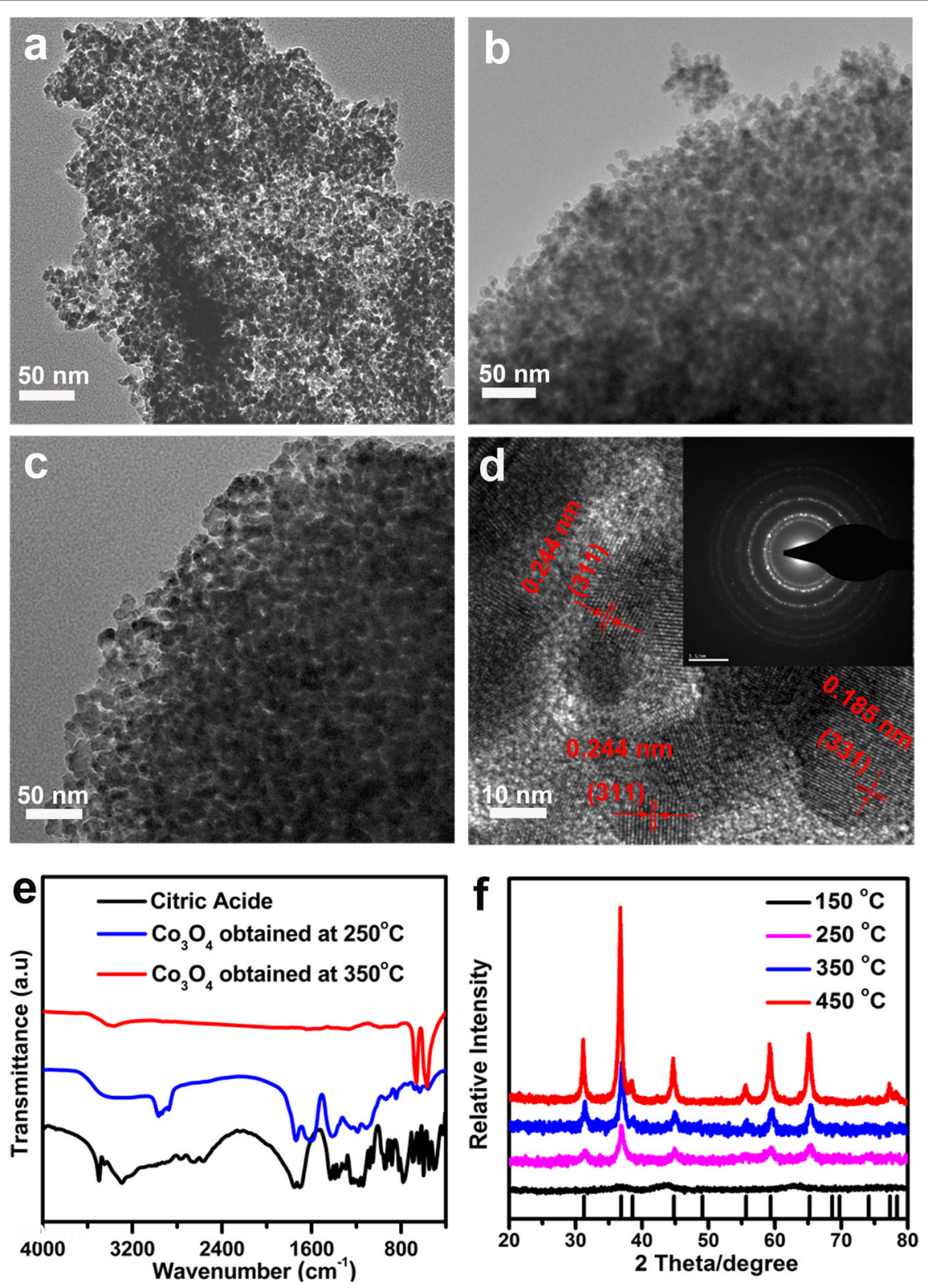

Fig. 1 Characterization of mesoporous $\mathrm{Co}_{3} \mathrm{O}_{4}$. TEM images of mesoporous $\mathrm{Co}_{3} \mathrm{O}_{4}$ obtained at (a) $250^{\circ} \mathrm{C}$, (b) $350{ }^{\circ} \mathrm{C}$, and $\mathbf{c} 450{ }^{\circ} \mathrm{C}$. $\mathbf{d} \mathrm{HRTEM}$ images of mesoporous $\mathrm{CO}_{3} \mathrm{O}_{4}$ obtained at $350^{\circ} \mathrm{C}$ and the corresponding SAED pattern shown in the inset. e FTIR spectra of citric acid and mesoporous $\mathrm{CO}_{3} \mathrm{O}_{4} \cdot \mathbf{f}$ XRD patterns of mesoporous $\mathrm{CO}_{3} \mathrm{O}_{4}$ at different calcination temperatures

The crystal phase of $\mathrm{Co}_{3} \mathrm{O}_{4}$ was confirmed by power Xray diffraction (PXRD). Figure if shows the evolution from the amorphous to the crystalline phase with an increase in calcination temperature from $150{ }^{\circ} \mathrm{C}$ to $450{ }^{\circ} \mathrm{C}$. The sample calcined at $250^{\circ} \mathrm{C}$ shows low crystallinity. After calcination at $350^{\circ} \mathrm{C}$, the XRD pattern displays wellresolved characteristic diffraction peaks, which can be well indexed to cobalt oxide with lattice parameters of $a=0.8048 \mathrm{~nm}, b=0.8048 \mathrm{~nm}, c=0.8048 \mathrm{~nm}$, and $\beta=90^{\circ}$ (JCPDS No. 43-1003), confirming the formation of a highly crystalline phase. Increasing the calcination temperature to $450^{\circ} \mathrm{C}$ causes additional crystal growth as well as further improvement in crystallinity. In addition, no characteristic peaks from other crystalline phases were detected, demonstrating the high purity of $\mathrm{Co}_{3} \mathrm{O}_{4}$. To investigate the morphology and mesostructural information, the as-synthesized samples were characterized by TEM and HRTEM. The walls of the mesopores are composed of ultra-small $\mathrm{Co}_{3} \mathrm{O}_{4}$ nanocrystals, and the nanocrystals gradually grow as the temperature increases from $250^{\circ} \mathrm{C}$ to $450^{\circ} \mathrm{C}$ (Fig. 1a-c). As shown in Fig. 1b, $\mathrm{Co}_{3} \mathrm{O}_{4}$ nanoparticles calcined at $350^{\circ} \mathrm{C}$ possess a uniform 

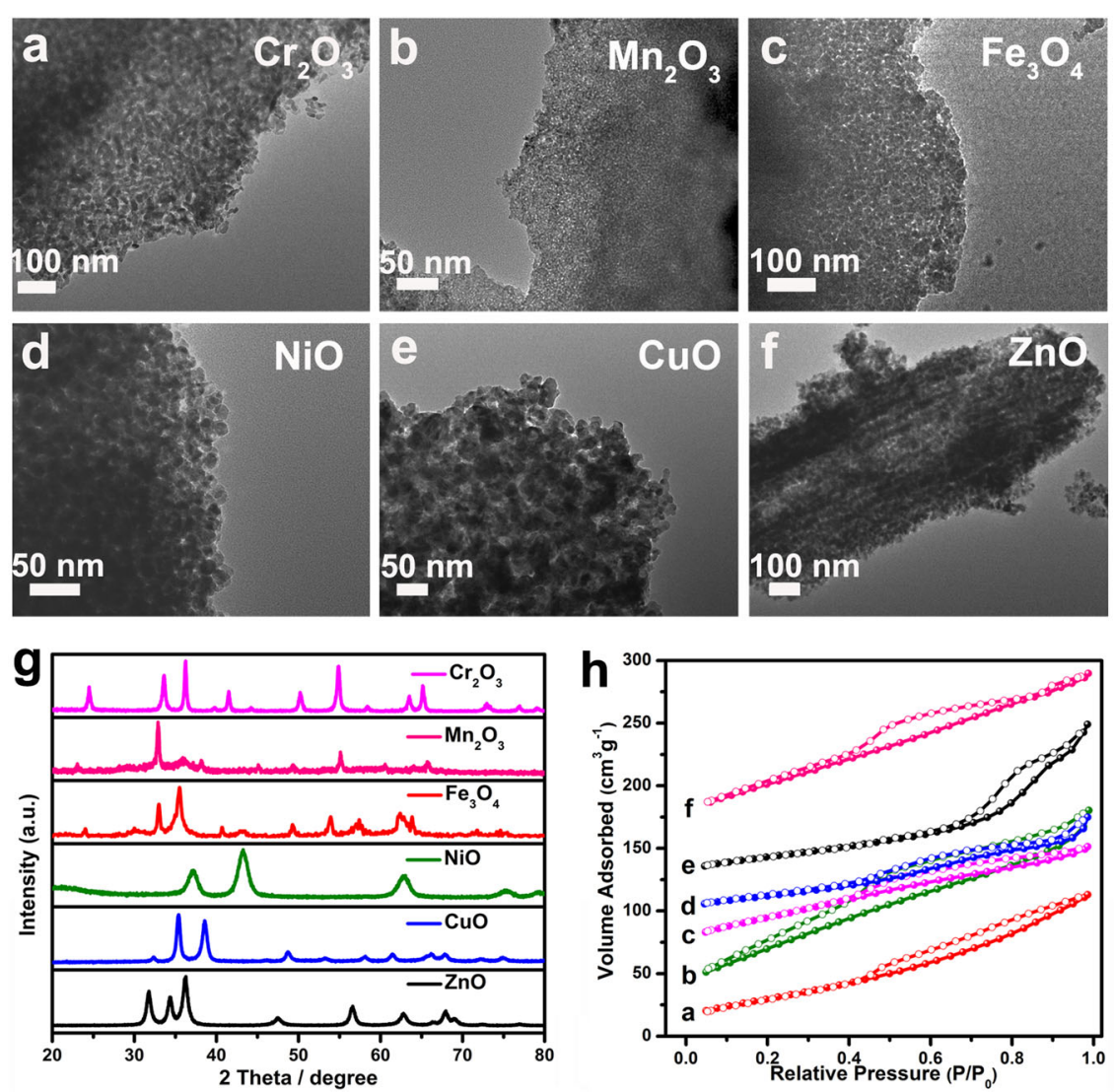

Fig. 2 Characterization of other mesoporous materials. a-f TEM images of different mesoporous transition metal oxides obtained at $350^{\circ} \mathrm{C}$. $\mathbf{g}$ XRD patterns of different mesoporous transition metal oxides obtained at $350^{\circ} \mathrm{C}$. $\mathbf{h ~} \mathrm{N}_{2}$ adsorption-desorption isotherms of different mesoporous transition metal oxides obtained at $350^{\circ} \mathrm{C}$. a-f correspond to $\mathrm{Fe}_{3} \mathrm{O}_{4}, \mathrm{NiO}, \mathrm{Cr}_{2} \mathrm{O}_{3}, \mathrm{CuO}, \mathrm{ZnO}$, and $\mathrm{Mn}_{2} \mathrm{O}_{3}$. The isotherm curves $(\mathbf{b}, \mathbf{c}, \mathbf{d}, \mathbf{e}$,$) and \mathbf{f}$ in $\mathbf{h}$ are shifted by $30,60,90,120$, and $150 \mathrm{~cm}^{3} \mathrm{~g}^{-1}$, STP, respectively, for clarity

size distribution of approximately $6 \mathrm{~nm}$, which is consistent with the result of $6.4 \mathrm{~nm}$ calculated by the Scherrer equation (according to Fig. 1f, blue line). The distinct lattice can be clearly observed in the HRTEM image (Fig. 1d), further revealing that the as-synthesized sample is well crystallized. The corresponding SAED, inset in Fig. 1d, shows a set of well-defined concentric rings, which clearly verifies the polycrystalline character of mesoporous $\mathrm{Co}_{3} \mathrm{O}_{4}$.

The nitrogen sorption-desorption isotherms of mesoporous $\mathrm{Co}_{3} \mathrm{O}_{4}$ obtained by calcination at different temperatures are shown in Figure S1 and Figure S2. After calcination at $350^{\circ} \mathrm{C}$ in air, the isotherms exhibit characteristic type-IV curves with distinct hysteresis loops close to $\mathrm{H}_{2}$ type, reflecting the existence of mesopores. The $\mathrm{BJH}$ adsorption pore diameter (inset in Figure S1) exhibits a narrow peak at $3.4 \mathrm{~nm}$ calculated from the adsorption branch, clearly indicating that the mesoporous $\mathrm{Co}_{3} \mathrm{O}_{4}$ prepared by the ligand-assisted self-assembly method possesses a well-defined and uniform pore size distribution. The corresponding specific surface area and pore volume of this material estimated from the BET method are $106 \mathrm{~m}^{2} \mathrm{~g}^{-1}$ and $0.24 \mathrm{~cm}^{3} \mathrm{~g}^{-1}$, respectively. As the calcination temperature increased from $350^{\circ} \mathrm{C}$ to $450{ }^{\circ} \mathrm{C}$, the specific surface area decreased from $106 \mathrm{~m}^{2} \mathrm{~g}^{-1}$ to $32 \mathrm{~m}^{2} \mathrm{~g}^{-1}$, while the pore size increased from $3.4 \mathrm{~nm}$ to $6.1 \mathrm{~nm}$.

To confirm the versatility of the method, crystalline $\mathrm{Cr}_{2} \mathrm{O}_{3}, \mathrm{Mn}_{2} \mathrm{O}_{3}, \mathrm{Fe}_{3} \mathrm{O}_{4}, \mathrm{NiO}, \mathrm{CuO}$, and $\mathrm{ZnO}$ with welldefined mesoporous structures were synthesized by this ligand-assisted self-assembly approach. The XRD patterns of the as-prepared samples all match well with their corresponding metal oxide phases (Fig. 2g): eskolaite for $\mathrm{Cr}_{2} \mathrm{O}_{3}$, hausmannite for $\mathrm{Mn}_{3} \mathrm{O}_{4}$, bunsenite for $\mathrm{NiO}$, and zinicite for $\mathrm{ZnO}$. The TEM images (Fig. 2a-f) of these samples, obtained at $350^{\circ} \mathrm{C}$, show that all the formed materials maintain their disordered worm-like mesoporous structures, and the walls of mesopores are constructed from small highly crystallized nanocrystals with similar morphological features. A similar twodimensional pore structure can be observed in the TEM 

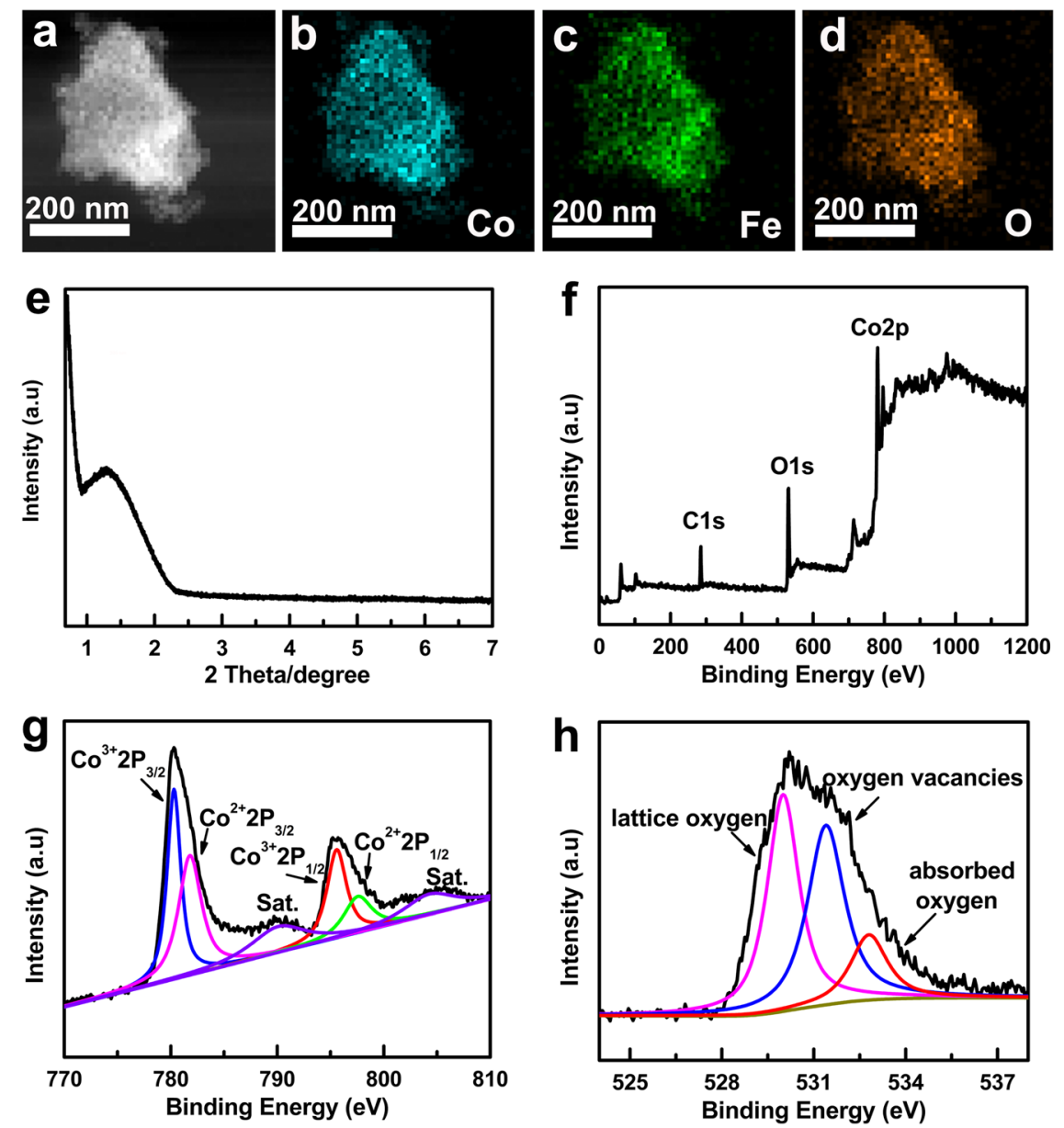

Fig. 3 Component analysis of the mesoporous materials. a Typical STEM image of mesoporous $\mathrm{CO}_{3} \mathrm{O}_{4} / \mathrm{Fe}_{3} \mathrm{O}_{4}(4: 1)$ composites and the corresponding elemental mapping of $\mathbf{b}$ cobalt, $\mathbf{c}$ iron, and $\mathbf{d}$ oxygen elements. e Small-angle XRD pattern of $\mathrm{ZnO}$. $\mathbf{f}$ Survey XPS spectrum of $\mathrm{CO}_{3} \mathrm{O}_{4}$. $\mathbf{g}$ High-resolution XPS Co $2 p$ spectrum and $\mathbf{h}$ high-resolution XPS O 1 s spectrum

image of $\mathrm{ZnO}$, and an individual $\mathrm{ZnO}$ channel has a width of $7.8 \mathrm{~nm}$ with rough surfaces. In contrast to other metal oxides, $\mathrm{ZnO}$ is prepared with ascorbic acid instead of citric acid. Compared with the other mesoporous metal oxides we obtained, the small-angle XRD pattern (Fig. 3e) of $\mathrm{ZnO}$ shows a more apparent diffraction between $1^{\circ}$ and $2^{\circ}$, indicating a relatively regular mesoporous structure, which is consistent with the TEM results. $\mathrm{N}_{2}$ adsorption-desorption isotherms and the corresponding pore size distribution curves of the obtained mesoporous transition metal oxides are shown in Fig. $2 \mathrm{~h}$ and Figure S6. The BET surface areas of the obtained samples are in the range of $68-205 \mathrm{~m}^{2} \mathrm{~g}^{-1}: 130 \mathrm{~m}^{2} \mathrm{~g}^{-1}$ for $\mathrm{Cr}_{2} \mathrm{O}_{3}$, $205 \mathrm{~m}^{2} \mathrm{~g}^{-1}$ for $\mathrm{Mn}_{2} \mathrm{O}_{3}, 127 \mathrm{~m}^{2} \mathrm{~g}^{-1}$ for $\mathrm{Fe}_{3} \mathrm{O}_{4}, 137 \mathrm{~m}^{2} \mathrm{~g}^{-1}$ for $\mathrm{NiO}, 68 \mathrm{~m}^{2} \mathrm{~g}^{-1}$ for $\mathrm{CuO}$, and $86 \mathrm{~m}^{2} \mathrm{~g}^{-1}$ for $\mathrm{ZnO}$.

This ligand-assisted self-assembly method can also be used for the fabrication of mesoporous materials with multicomponent structures. Mesoporous $\mathrm{Co}_{3} \mathrm{O}_{4} / \mathrm{Fe}_{3} \mathrm{O}_{4}$, $\mathrm{Co}_{3} \mathrm{O}_{4} / \mathrm{NiO}$, and $\mathrm{Fe}_{3} \mathrm{O}_{4} / \mathrm{NiO}$ composites with controlled metal molar ratios were synthesized successfully. The specific surface areas are in a wide range from $87 \mathrm{~m}^{2} \mathrm{~g}^{-1}$ to $174 \mathrm{~m}^{2} \mathrm{~g}^{-1}$, and the pore volumes ranged from $0.131 \mathrm{~m}^{3} \mathrm{~g}^{-1}$ to $0.310 \mathrm{~m}^{3} \mathrm{~g}^{-1}$. The small-angle XRD patterns of single- and multi-metal oxides are shown in Figure S4 and Figure S5. Concrete mesostructural data and the corresponding nitrogen sorption-desorption isotherms of these samples are summarized in Table S1 and Figures S7-9. Taking the $\mathrm{Co}_{3} \mathrm{O}_{4} / \mathrm{Fe}_{3} \mathrm{O}_{4}$ composition as an example, the chemical compositions were verified by XRD (Figure S10). ICP analysis shows that the $\mathrm{Co} / \mathrm{Fe}$ molar ratio is approximately $4: 1$, which is in accordance with the initial amount of metal nitrates added during preparation of this composite material. Figure $3 \mathrm{a}$ and Figure S11 show the STEM and TEM images of the mesoporous $\mathrm{Co}_{3} \mathrm{O}_{4} / \mathrm{Fe}_{3} \mathrm{O}_{4}$ (4:1) composites. The corresponding EDX elemental mapping images of $\mathrm{Co}$, Fe, and $\mathrm{O}$ (Fig. 3b, c, d) reveal a homogeneous distribution of Co and $\mathrm{Fe}$ in the mesoporous framework. We believe that our 
ligand-assisted self-assembly approach is a versatile method for the synthesis of both single- and multitransition metal oxide composites.

The chemical states of $\mathrm{Co}_{3} \mathrm{O}_{4}$ were examined by X-ray photoelectron spectroscopy (XPS). A survey scan (Fig. 3f) revealed that the surface mainly consists of $\mathrm{Co}, \mathrm{O}$, and $\mathrm{C}$. As shown in Fig. 3g, the peaks at $\sim 780.3$ and $\sim 795.5 \mathrm{eV}$ can be indexed to $\mathrm{Co}^{3+} 2 \mathrm{p}_{1 / 2}$ and $\mathrm{Co}^{3+} 2 \mathrm{p}_{3 / 2}$, and those located at $\sim 781.8$ and $\sim 797.5 \mathrm{eV}$ correspond to $\mathrm{Co}^{2+} 2 \mathrm{p}_{1 / 2}$ and $\mathrm{Co}^{2+} 2 \mathrm{p}_{3 / 2}$, suggesting that two valence states (octahedral $\mathrm{Co}^{3+}$ and tetrahedral $\mathrm{Co}^{2+}$ ) coexist in $\mathrm{Co}_{3} \mathrm{O}_{4}$. The $\mathrm{O} 1 \mathrm{~s}$ spectrum (Fig. 3h) can be deconvoluted into three distinct peaks: oxygen ions in the crystal lattice (at 530.1 $\mathrm{eV}$ ), oxygen vacancies (at $532.2 \mathrm{eV}$ ), and absorbed oxygen species (at $531.2 \mathrm{eV})^{23}$. The thermogravimetric analysis trace (Figure S12) obtained after evaporation at $120^{\circ} \mathrm{C}$ shows two thermal events: a large weight loss at $180^{\circ} \mathrm{C}$ and a smaller weight loss at $350^{\circ} \mathrm{C}$, which correspond to conversion from $\mathrm{CoCO}_{3}$ to $\mathrm{Co}_{3} \mathrm{O}_{4}$ and the combustion of residual carbon, respectively.

To confirm the positive role of the carboxyl ligand, control experiments without ligands were performed. The surface areas show a dramatic declining trend for some of the transition metal oxides, decreasing from 130 to $26 \mathrm{~m}^{2} \mathrm{~g}^{-1}$ for $\mathrm{Cr}_{2} \mathrm{O}_{3}$, from 68 to $16 \mathrm{~m}^{2} \mathrm{~g}^{-1}$ for $\mathrm{CuO}$, and from 86 to $31 \mathrm{~m}^{2} \mathrm{~g}^{-1}$ for $\mathrm{ZnO}$ (Figure $\mathrm{S} 12$ ). In addition, the crystallinity of $\mathrm{Mn}_{2} \mathrm{O}_{3}$ also decreased. $\mathrm{Mn}_{2} \mathrm{O}_{3}$ synthesized without the addition of carboxyl ligands is not crystalline until the calcination temperature is increased to $450{ }^{\circ} \mathrm{C}$, while the oxide is already highly crystallized at $350^{\circ} \mathrm{C}$ in the presence of carboxyl ligands (Figure S13).

Water electrolysis is considered a promising way to overcome the problem of fossil fuel depletion. Transition metal oxides such as $\mathrm{Co}_{3} \mathrm{O}_{4}$ and $\mathrm{NiO}$ have been regarded as effective catalysts to replace the precious iridium and ruthenium oxides in the $\mathrm{OER}^{24-27}$. Here, we assessed the OER properties in a standard three-electrode system. During the electrochemical measurement, oxygen evolved rapidly from the catalyst surface. The overpotential at a current density of $10 \mathrm{~mA} \mathrm{~cm}^{-2}$ is relevant to the watersplitting reaction. Mesoporous $\mathrm{Co}_{3} \mathrm{O}_{4}$ samples obtained at different temperatures were tested for the OER to confirm the optimal calcination temperature of the electrocatalysts. As shown in Figure S14, the overpotential of mesoporous $\mathrm{Co}_{3} \mathrm{O}_{4}$ calcined at $350^{\circ} \mathrm{C}$ is $353 \mathrm{mV}$, while $\mathrm{Co}_{3} \mathrm{O}_{4}$ calcined at $250^{\circ} \mathrm{C}$, possessing lower crystallinity, shows a high overpotential of $466 \mathrm{mV}$, and $\mathrm{Co}_{3} \mathrm{O}_{4}$ calcined at $450^{\circ} \mathrm{C}$, possessing higher crystallinity, shows an overpotential of $391 \mathrm{mV}$. These results demonstrate that the samples calcined at $350^{\circ} \mathrm{C}$ show the best performance. To corroborate the existence of mesopores playing an active role in the OER, commercial $\mathrm{Co}_{3} \mathrm{O}_{4}$ nanoparticles,
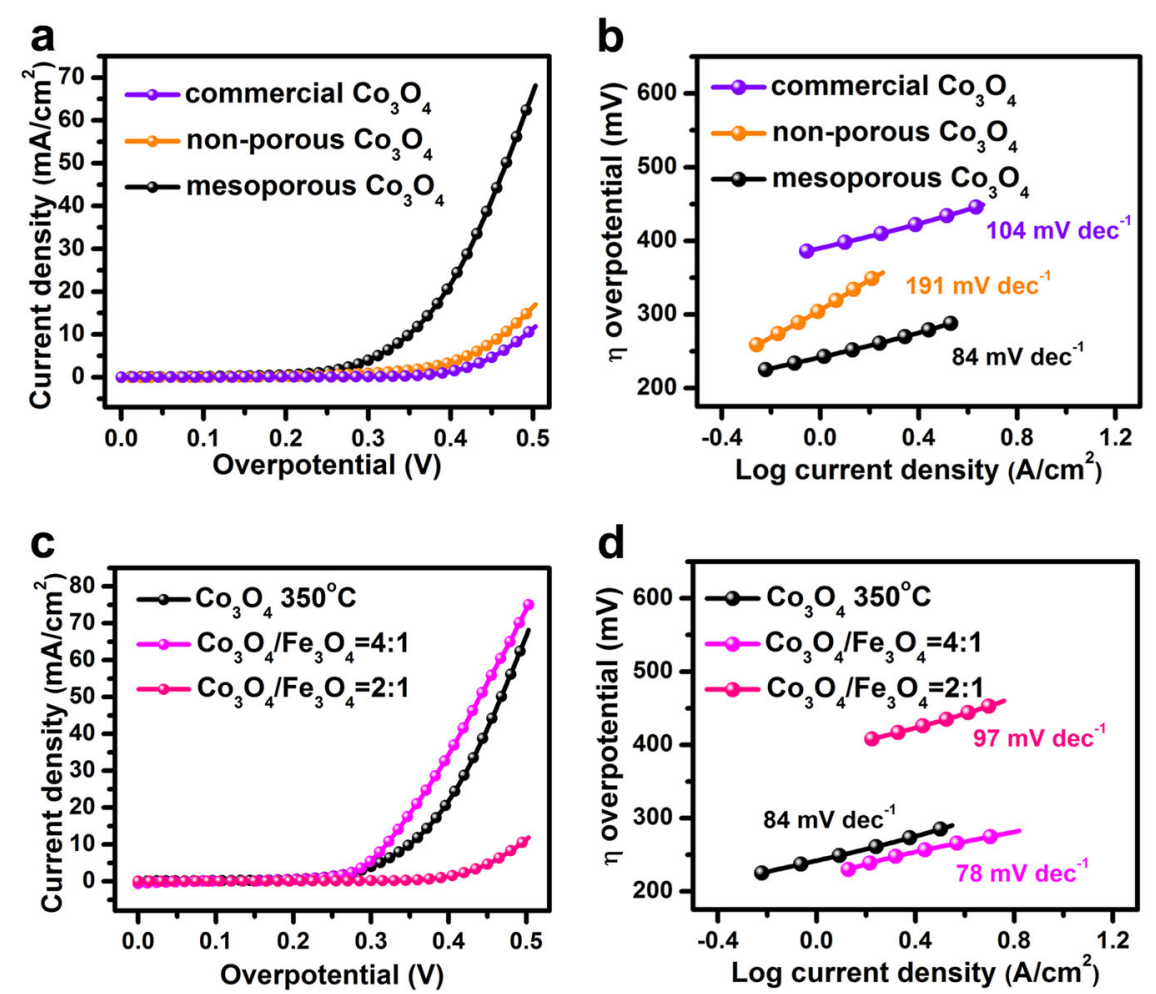

Fig. 4 OER performance of different types of catalysts. $\mathbf{a}$, $\mathbf{b} \mathrm{LSV}$ curves and Tafel plots of different types of $\mathrm{CO}_{3} \mathrm{O}_{4}$. $\mathbf{c}$, $\mathbf{d}$ LSV curves and Tafel plots of different $\mathrm{CO}_{3} \mathrm{O}_{4} / \mathrm{Fe}_{3} \mathrm{O}_{4}$ ratios 
Table 1 Comparison of catalyst activity in the OER

\begin{tabular}{|c|c|c|c|c|c|c|}
\hline Catalyst & $\begin{array}{l}\text { Mass loading } \\
\left(\mu \mathrm{g} \mathrm{cm}^{-2}\right)\end{array}$ & $\begin{array}{l}\eta \text { at } J=10 \mathrm{~mA} \\
\mathrm{~cm}^{-2}(\mathrm{mV})\end{array}$ & $\begin{array}{l}\text { Tafel slope } \\
\left(\mathrm{mV} \operatorname{dec}^{-1}\right)\end{array}$ & $\begin{array}{l}\text { Mass activity at } \\
\eta=0.4 \mathrm{~V}\left(\mathrm{~A} \mathrm{~g}^{-1}\right)\end{array}$ & $\begin{array}{l}\text { TOF at } \\
\eta=0.4 \mathrm{~V}\left(\mathrm{~s}^{-1}\right)\end{array}$ & Ref. \\
\hline $\begin{array}{l}\mathrm{CO}_{3} \mathrm{O}_{4} / \mathrm{Fe}_{3} \mathrm{O}_{4}(4: 1) \\
\text { composites }\end{array}$ & 500 & 322 & 78 & 34.4 & 0.0215 & $\begin{array}{l}\text { Our } \\
\text { work }\end{array}$ \\
\hline $\mathrm{CO}_{3} \mathrm{O}_{4}$ & 500 & 353 & 84 & 21.5 & 0.0314 & $\begin{array}{l}\text { Our } \\
\text { work }\end{array}$ \\
\hline $\mathrm{CO}_{3} \mathrm{O}_{4}$-MNTs & 531 & 353 & 80 & - & - & 28 \\
\hline $\mathrm{Co}_{3} \mathrm{O}_{4} @ \mathrm{CoO} \mathrm{SC}$ & 25 & 430 & 89 & 234.0 & 0.0487 & 29 \\
\hline $\mathrm{Co}_{0.54} \mathrm{Fe}_{0.46} \mathrm{OOH}$ & - & 390 & 47 & 200 at $\eta=0.39 \mathrm{~V}$ & 0.0225 & 30 \\
\hline CoOx-4-h nanoplates & 500 & 306 & 61 & - & 0.0030 & 31 \\
\hline $\mathrm{Fe}_{1} \mathrm{CO}_{1}-\mathrm{ONS}$ & 360 & 308 & 36.8 & 54.9 at $\eta=0.35 \mathrm{~V}$ & $\begin{array}{l}0.0214 \text { at } \\
\eta=0.35 \mathrm{~V}\end{array}$ & 32 \\
\hline
\end{tabular}

non-porous $\mathrm{Co}_{3} \mathrm{O}_{4}$ obtained at $650{ }^{\circ} \mathrm{C}$, and mesoporous $\mathrm{Co}_{3} \mathrm{O}_{4}$ obtained at $350^{\circ} \mathrm{C}$ were tested for the OER. As shown in Fig. $4 \mathrm{a}$, the overpotential of commercial $\mathrm{Co}_{3} \mathrm{O}_{4}$ is $490 \mathrm{mV}$, and that of non-porous $\mathrm{Co}_{3} \mathrm{O}_{4}$ is $464 \mathrm{mV}$, which are both much higher than that of mesoporous $\mathrm{Co}_{3} \mathrm{O}_{4}$, indicating that mesopores provided the best OER performance. This obvious change can be ascribed to the introduction of porous structures. The mesopores not only contribute more catalytic active sites but also facilitate the detachment of oxygen bubbles from the electrode surface, which cooperatively promote the catalytic activity of $\mathrm{Co}_{3} \mathrm{O}_{4}$. Figure $4 \mathrm{c}$ shows the LSV curves of the pure mesoporous $\mathrm{Co}_{3} \mathrm{O}_{4}$ and $\mathrm{Co}_{3} \mathrm{O}_{4} / \mathrm{Fe}_{3} \mathrm{O}_{4}$ composite electrodes calcined at $350{ }^{\circ} \mathrm{C}$. The $\mathrm{Co}_{3} \mathrm{O}_{4} / \mathrm{Fe}_{3} \mathrm{O}_{4}(4: 1)$ composite requires an overpotential of only $322 \mathrm{mV}$ to achieve a current density of $10 \mathrm{~mA} \mathrm{~cm}^{-2}$, which is superior to most previous reports on non-precious OER electrocatalysts in alkaline aqueous electrolytes (Table 1$)^{28-32}$. For comparison, the $\mathrm{Co}_{3} \mathrm{O}_{4} / \mathrm{Fe}_{3} \mathrm{O}_{4}(2: 1)$ composite demands an overpotential of $494 \mathrm{mV}$ to achieve a current density of $10 \mathrm{~mA} \mathrm{~cm}^{-2}$, and no obvious current response is observed when the working electrode film is prepared by pure mesoporous $\mathrm{Fe}_{3} \mathrm{O}_{4}$ (Figure S15). The enhancement of the catalytic performance when going from pure $\mathrm{Co}_{3} \mathrm{O}_{4}$ to the $\mathrm{Co}_{3} \mathrm{O}_{4} / \mathrm{Fe}_{3} \mathrm{O}_{4}$ (4:1) composite can be attributed to synergistic effects and interface effects between $\mathrm{Co}_{3} \mathrm{O}_{4}$ and $\mathrm{Fe}_{3} \mathrm{O}_{4}$, which promote charge flow in the working electrode and can lead to the efficient transport of electrons and ions in this composite material $^{33,34}$. Furthermore, the difference in the degree of electrolyte infiltration among the different mesoporous materials can also influence the catalytic activity. Under the premise of not changing the predominance of $\mathrm{Co}_{3} \mathrm{O}_{4}$, the introduction of $\mathrm{Fe}_{3} \mathrm{O}_{4}$ provides a larger BET (from 106 to $170 \mathrm{~m}^{2} / \mathrm{g}$ ) and a higher pore volume (from 0.235 to
$0.310 \mathrm{~cm}^{3} / \mathrm{g}$ ), which allows the electrolyte solution to infiltrate into the porous electrode more adequately. However, the catalytic activity of the composite materials decreases with increasing $\mathrm{Co} / \mathrm{Fe}$ ratio from $4: 1$ to $2: 1$, because pure $\mathrm{Fe}_{3} \mathrm{O}_{4}$ does not show any catalytic activity and excessively increasing the proportion of $\mathrm{Fe}_{3} \mathrm{O}_{4}$ is not conducive to catalytic activity in the OER. The catalytic activities of other $\mathrm{Co} / \mathrm{Fe}$ ratios are shown in Figure S16.

To advance our understanding of the enhancement in OER activity, the electrochemically active surface area (ECSA) of the as-prepared catalysts was tested by electrochemical capacitance surface area measurements ${ }^{35-38}$. The ECSA is positively proportional to the double-layer capacitance $\left(C_{\mathrm{dl}}\right)$ (Fig. $\left.5 \mathrm{a}, \mathrm{b}\right)$, which is equivalent to half of the slope. The obtained capacitive currents are plotted as a function of the scan rate in Fig. 5c. The capacitance of $\mathrm{Co}_{3} \mathrm{O}_{4} / \mathrm{Fe}_{3} \mathrm{O}_{4}$ (4:1) was calculated to be $144.7 \mathrm{mF} \mathrm{cm}^{-2}$, which is higher than that of mesoporous $\mathrm{Co}_{3} \mathrm{O}_{4}$ $\left(83.7 \mathrm{mF} \mathrm{cm}^{-2}\right)$. The results suggest that more exposed active sites are available for $\mathrm{Co}_{3} \mathrm{O}_{4} / \mathrm{Fe}_{3} \mathrm{O}_{4}$ (4:1), which contribute to better electrocatalytic performance.

The catalytic OER kinetics of the catalysts were investigated using Tafel plots (log $j-\eta$ ) obtained from the normalized polarization curves ${ }^{39,40}$. As shown in Fig. $4 \mathrm{~b}$, $\mathrm{d}$, the Tafel slope of the $\mathrm{Co}_{3} \mathrm{O}_{4} / \mathrm{Fe}_{3} \mathrm{O}_{4}$ (4:1) composite is $78 \mathrm{mV} \mathrm{dec}^{-1}$, which is smaller than that of pure mesoporous $\mathrm{Co}_{3} \mathrm{O}_{4}\left(84 \mathrm{mV} \mathrm{dec}^{-1}\right)$, indicating that the mesoporous $\mathrm{Co}_{3} \mathrm{O}_{4} / \mathrm{Fe}_{3} \mathrm{O}_{4}$ (4:1) composite is a more efficient catalyst and has favorable kinetics during the OER in alkaline medium.

Chronoamperometric measurements were performed to investigate the long-term durability in the OER. The durability of the electrocatalysts was tested at $10 \mathrm{~mA} \mathrm{~cm}^{-2}$ in $1 \mathrm{M} \mathrm{KOH}$ solution at room temperature. As observed in Fig. $5 d$, both the pure $\mathrm{Co}_{3} \mathrm{O}_{4}$ and $\mathrm{Co}_{3} \mathrm{O}_{4} / \mathrm{Fe}_{3} \mathrm{O}_{4}(4: 1)$ 

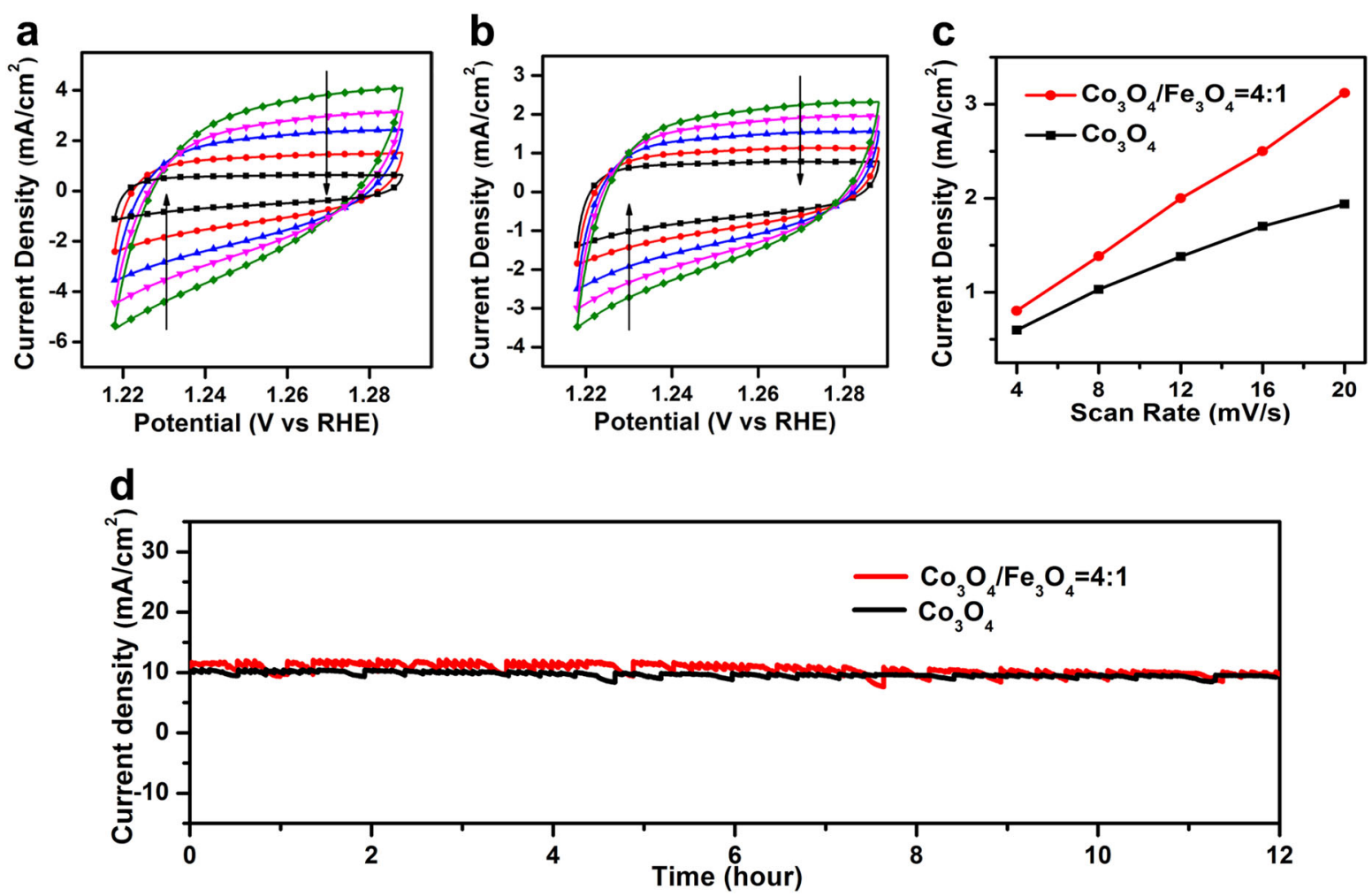

Fig. 5 Assessment of electrochemical performance and stability. $\mathrm{CVs}$ of $\mathbf{a} \mathrm{CO}_{3} \mathrm{O}_{4} / \mathrm{Fe}_{3} \mathrm{O}_{4}(4: 1)$ and $\mathbf{b} \mathrm{Co}_{3} \mathrm{O}_{4}$ at different scan rates of $4 \mathrm{mV} / \mathrm{s}, 8 \mathrm{mV} / \mathrm{s}$, $12 \mathrm{mV} / \mathrm{s}, 16 \mathrm{mV} / \mathrm{s}$, and $20 \mathrm{mV} / \mathrm{s}$. c The capacitive current density at $1.25 \mathrm{~V}$ as a function of scan rate. $\mathbf{d}$ Chronoamperometry curves of pure mesoporous $\mathrm{CO}_{3} \mathrm{O}_{4}$ and mesoporous $\mathrm{Co}_{3} \mathrm{O}_{4} / \mathrm{Fe}_{3} \mathrm{O}_{4}$ (4:1) composites

nanocomposite electrodes show excellent electrochemical durability over a 12-h continuous experiment. Their excellent long-term durability can be attributed to the formation of an interconnected metal oxide network after calcination, which is robust enough for the OER. No obvious changes were observed in the TEM image compared with the untested samples (Figure S17), further confirming the robustness of the as-prepared mesoporous $\mathrm{Co}_{3} \mathrm{O}_{4}$. The slight current density decrease is due to catalysts falling off the glassy carbon electrode during the oxygen evolution process. The excellent electrochemical performance convinces us that a ligand-assisted evaporation-induced self-assembly strategy opens a new way to synthesizing more efficient catalysts for the OER.

\section{Conclusion}

In conclusion, a general ligand-assisted self-assembly approach has been demonstrated to synthesize mesoporous transition metal oxides with a high degree of crystallinity. Citric acid or ascorbic acid is employed as a coordination agent, and chelation between the metal and ligand can effectively slow the hydrolysis and condensation rates of the metal precursors. This approach is high yielding (measured in grams) and insensitive to synthesis conditions. Almost all transition metal oxides in the periodic table can be synthesized by this widely applicable method. These obtained mesoporous materials possess high specific surface areas and large pore volumes, which provide abundant reaction sites for the electrolyte, making them possible for use as remarkable electrochemical materials. As a demonstration, the mesoporous $\mathrm{Co}_{3} \mathrm{O}_{4} /$ $\mathrm{Fe}_{3} \mathrm{O}_{4}$ (4:1) nanocomposite exhibits an exceptional catalytic ability in water splitting with low overpotential $\left(322 \mathrm{mV}\right.$ at $\left.10 \mathrm{~mA} \mathrm{~cm}^{-2}\right)$, large anodic current, and longterm durability. The present method offers a new way to prepare mesoporous transition metal oxides and multimetal oxide composites for a wide range of applications.

\footnotetext{
Acknowledgements

This work was supported by the Young Thousand Talented Program and the National Natural Science Foundation of China $(21671073,21621001$, and 21671074), the "111" Project of the Ministry of Education of China (B17020), and Program for JLU Science and Technology Innovative Research Team.
}

Author contributions

Z.A.Q. designed the experiments. D.Y.F. performed the experiments and analyzed the data. T.N.G. and T.W. performed the $\mathrm{N}_{2}$ adsorption experiments, A.L. and K.Q.L. carried out the TEM imaging. M.H.F. and Q.S.H. discussed the results and commented on the manuscript. 


\section{Competing interests}

The authors declare no competing interests.

\section{Publisher's note}

Springer Nature remains neutral with regard to jurisdictional claims in published maps and institutional affiliations.

Supplementary Information is available for this paper at https://doi.org/ 10.1038/s41427-018-0072-z.

Received: 8 April 2018 Revised: 21 June 2018 Accepted: 26 June 2018. Published online: 21 August 2018

\section{References}

1. Sarkar, D. et al. A subthermionic tunnel field-effect transistor with an atomically thin channel. Nature 526, 91-95 (2015).

2. $\mathrm{Yu}$, J. et al. Nature-inspired 2D-mosaic 3D-gradient mesoporous framework: bimetal oxide dual-composite strategy toward ultrastable and high-capacity lithium storage. ACS Nano 12, 2035-2047 (2018).

3. Ba, N., Zhu, L., Zhang, G., Li, J. \& Li, H. Facile synthesis of 3D CuO nanowire bundle and its excellent gas sensing and electrochemical sensing properties. Sens. Actuators, B 227, 142-148 (2016).

4. Zhu, S. et al. Ultrathin-nanosheet-induced synthesis of 3D transition metal oxides networks for lithium ion battery anodes. Adv. Funct. Mater. 27, 1605017 (2017).

5. Li, G. et al. Pomegranate-inspired design of highly active and durable bifunctional electrocatalysts for rechargeable metal-air batteries. Angew. Chem. Int. Ed. 55, 4977-4982 (2016).

6. Hua, B. et al. A coupling for success: controlled growth of $\mathrm{Co} / \mathrm{CoO}_{x}$ nanoshoots on perovskite mesoporous nanofibres as high-performance trifunctional electrocatalysts in alkaline condition. Nano Energy 32, 247-254 (2017).

7. Nasi, L. et al. Mesoporous single-crystal ZnO nanobelts: supported preparation and patterning. Nanoscale 5, 1060-1066 (2013).

8. Ma, Y. et al. A chelation-induced cooperative self-assembly methodology for the synthesis of mesoporous metal hydroxide and oxide nanospheres. Nanoscale 10, 5731-5737 (2018).

9. Namai, A. et al. Hard magnetic ferrite with a gigantic coercivity and high frequency millimetre wave rotation. Nat. Commun. 3, 1035 (2012).

10. Deng, $X_{.}$Chen, K. \& Tüysüz, H. Protocol for the nanocasting method: preparation of ordered mesoporous metal oxides. Chem. Mater. 29, 40-52 (2016).

11. $\mathrm{Fu}, \mathrm{S}$. et al. Highly ordered mesoporous bimetallic phosphides as efficient oxygen evolution electrocatalysts. ACS Energy Lett. 1, 792-796 (2016).

12. Lee, J. et al. Direct access to thermally stable and highly crystalline mesoporous transition-metal oxides with uniform pores. Nat. Mater. 7, 222-228 (2008).

13. Fan, J., Boettcher, S. W. \& Stucky, G. D. Nanoparticle assembly of ordered multicomponent mesostructured metal oxides via a versatile sol-gel process. Chem. Mater. 18, 6391-6396 (2006).

14. Poyraz, A. S., Kuo, C.-H., Biswas, S., King'ondu, C. K. \& Suib, S. L. A general approach to crystalline and monomodal pore size mesoporous materials. Nat. Commun. 4, 2952 (2013).

15. Huang, L. et al. Controlled synthesis and flexible self-assembly of monodisperse Au@Semiconductor core/shell hetero-nanocrystals into diverse superstructures. Chem. Mater. 29, 2355-2363 (2017).

16. Huang, J. et al. Bottom-up assembly of hydrophobic nanocrystals and graphene nanosheets into mesoporous nanocomposites. Langmuir $\mathbf{3 0}$ 4434-4440 (2014).

17. Patra, A. K, Das, S. K. \& Bhaumik, A. Self-assembled mesoporous TiO2 spherical nanoparticles by a new templating pathway and its enhanced photoconductivity in the presence of an organic dye. J. Mater. Chem. 21, 3925-3930 (2011).
18. Paul, M., Pal, N., Mondal, J., Sasidharan, M. \& Bhaumik, A. New mesoporous magnesium-alminum mixed oxide and its catalytic activity in liquid phase Baeyer-Villiger oxidation reaction. Chem. Eng. Sci. 71, 564-572 (2012).

19. Zhang, J. et al. Ligand-assisted assembly approach to synthesize large-pore ordered mesoporous titania with thermally stable and crystalline framework. Adv. Energy Mater. 1, 241-248 (2011).

20. Wang, Z. et al. Controlled synthesis of ordered mesoporous carbon-cobalt oxide nanocomposites with large mesopores and graphitic walls. Chem. Mater. 28, 7773-7780 (2016)

21. Das, S. K, Bhunia, M. K., Sinha, A. K. \& Bhaumij, A. Self-assembled mesoporous zirconia and sulfated zirconia nanoparticles synthesized by triblock copolymer as template. J. Phys. Chem. C. 113, 8918-8923 (2009).

22. Zhou, X. et al. Chelation-assisted soft-template synthesis of ordered mesoporous zinc oxides for low concentration gas sensing. J. Mater. Chem. A 4, 15064-15071 (2016).

23. Cai, Z. et al. Single-crystalline ultrathin $\mathrm{CO}_{3} \mathrm{O}_{4}$ nanosheets with massive vacancy defects for enhanced electrocatalysis. Adv. Energy Mater. 8, 1701694 (2018).

24. Liang, $\mathrm{Y}$. et al. $\mathrm{CO}_{3} \mathrm{O}_{4}$ nanocrystals on graphene as a synergistic catalyst for oxygen reduction reaction. Nat. Mater. 10, 780-786 (2011).

25. Khalid, M., Honorato, A. M. B., Varela, H. \& Dai, L. Multifunctional electrocatalysts derived from conducting polymer and metal organic framework complexes. Nano Energy 45, 127-135 (2018).

26. Subbaraman, R. et al. Trends in activity for the water electrolyser reactions on 3d M (Ni,Co,Fe,Mn) hydr(oxy)oxide catalysts. Nat. Mater. 11, 550-557 (2012).

27. Wang, Y. et al. Bio-inspired leaf-mimicking nanosheet/nanotube heterostructure as a highly efficient oxygen evolution catalyst. Adv. Sci. 2, 1500003 (2015).

28. Wang, H., Zhuo, S., Liang, Y., Han, X. \& Zhang, B. General self-template synthesis of transition-metal oxide and chalcogenide mesoporous nanotubes with enhanced electrochemical performances. Angew. Chem. Int. Ed. 55, 9055-9059 (2016).

29. Tung, C.-W. et al. Reversible adapting layer produces robust single-crystal electrocatalyst for oxygen evolution. Nat. Commun. 6, 8106 (2015).

30. Zhang, X. et al. Effective construction of high-quality iron oxy-hydroxides and Co-doped iron oxy-hydroxides nanostructures: towards the promising oxygen evolution reaction application. Sci. Rep. 7, 43590 (2017).

31. $\mathrm{Xu}, \mathrm{W}$. et al. Porous cobalt oxide nanoplates enriched with oxygen vacancies for oxygen evolution reaction. Nano Energy 43, 110-116 (2018).

32. Zhuang, L. et al. Ultrathin iron-cobalt oxide nanosheets with abundant oxygen vacancies for the oxygen evolution reaction. Adv. Mater. 29, 1606793 (2017).

33. Pan, Y. et al. Core-shell ZIF-8@ZIF-67-derived CoP nanoparticle-embedded Ndoped carbon nanotube hollow polyhedron for efficient overall water splitting. J. Am. Chem. Soc. 140, 2610-2618 (2018).

34. Wang, J. et al. Synergistic effect between metal-nitrogen-carbon sheets and $\mathrm{NiO}$ nanoparticles for enhanced electrochemical water-oxidation performance. Angew. Chem. Int. Ed. 54, 10530-10534 (2015).

35. Wu, A. et al. Integrating the active OER and HER components as the heterostructures for the efficient overall water splitting. Nano Energy 44, 353-363 (2018).

36. Deng, S. et al. Hollow $\mathrm{TiO}_{2} @ \mathrm{Co}_{9} \mathrm{~S}_{8}$ core-branch arrays as bifunctional electrocatalysts for efficient oxygen/hydrogen production. Adv. Sci. 5, 1700772 (2018).

37. Deng, S. et al. Directional construction of vertical nitrogen-doped $1 \mathrm{~T}-2 \mathrm{H}$ $\mathrm{MoSe}_{2} /$ graphene shell/core nanoflake arrays for efficient hydrogen evolution reaction. Adv. Mater. 29, 1700748 (2017).

38. $\mathrm{Yu}, \mathrm{M}$. et al. Dual-doped molybdenum trioxide nanowires: a bifunctional anode for fiber-shaped asymmetric supercapacitors and microbial fuel cells. Angew. Chem. Int. Ed. 55, 6762-6766 (2016).

39. Zhang, Y. et al. 3D porous hierarchical nickel-molybdenum nitrides synthesized by RF plasma as highly active and stable hydrogen-evolution-reaction electrocatalysts. Adv. Energy Mater. 6, 1600221 (2016).

40. Cao, L.-M., Wang, J.-W., Zhong, D.-C. \& Lu, T. -B. Template-directed synthesis of sulphur doped NiCoFe layered double hydroxide porous nanosheets with enhanced electrocatalytic activity for the oxygen evolution reaction. J. Mater. Chem. A 6, 3224-3230 (2018). 